\title{
The Urgent Need for Management of Biological Samples and Data Accessibility in Latin America
}

\author{
Rodrigo José Vargas ${ }^{1,2,3 *}$ and Oscar M. Cobar ${ }^{1,3,4}$ \\ ${ }^{1}$ Escuela de Estudios de Postgrado, Facultad de Ciencias Médicas, Universidad de San Carlos de Guatemala, Guatemala City, \\ Guatemala, ${ }^{2}$ Universidad Galileo, Guatemala City, Guatemala, ${ }^{3}$ Latin American Network for the Implementation and Validation of \\ Pharmacogenomic Clinical Guidelines (RELIVAF-CYTED), Madrid, Spain, ${ }^{4}$ Universidad del Istmo, Fraijanes, Guatemala
}

Keywords: biobank, Amerindian, COVID-19, mestizo, diversity

\section{INTRODUCTION}

Elucidation of the human genome has increased understanding of human body responses to drug administration (Oprea et al., 2018; Nabirotchkin et al., 2020). Likewise, recent studies on human genetic diversity have shown that it is still necessary to delve into individual genetic differences, the adverse effects associated with drug metabolism, drug response variability with the diet, and even the human microbiome (Sharma et al., 2019). Access to biological samples in Latin America is essential

OPEN ACCESS

Edited by:

Matias F. Martinez, University of Chile, Chile

Reviewed by:

M. Isabel Lucena, University of Malaga, Spain Alfonso Dueñas-González, National Autonomous University of Mexico, Mexico

*Correspondence:

Rodrigo José Vargas rodrigovargas@galileo.edu

Specialty section:

This article was submitted to

Pharmacogenetics and

Pharmacogenomics,

a section of the journal

Frontiers in Pharmacology

Received: 21 October 2020 Accepted: 15 February 2021

Published: 19 March 2021

Citation:

Vargas RJ and Cobar OM (2021) The Urgent Need for Management of Biological Samples and Data Accessibility in Latin America. Front. Pharmacol. 12:620043. doi: 10.3389/fphar.2021.620043 to further understanding the presence of genes that may be associated with adverse effects and pharmacological interactions due to their diversity of populations and in anticipating the effects of new treatments.

The Coronavirus disease 2019 (COVID-19) pandemic has reinforced the urgent need to study the genetic differences among people with mild symptoms and those with complex responses to the disease (Ovsyannikova et al., 2020). During the pandemic, different drugs have been studied in the search for therapeutic alternatives to combat it, mainly due to the "Solidarity Trial" and "Repurposing Drugs" initiatives of the World Health Organization (OMS) (Harrison, 2020). Similarly, new drugs for actual and future diseases can be designed by using pharmacogenetic information. As an example, due to the diversity of therapeutic action mechanisms of a drug, it is necessary to in parallel study human cell susceptibility to the entry of SARS-CoV-2 in genetic world populations. Pharmacogenetics studies of their allele variants are essential. This approach is imperative in enabling national health systems to make informed decisions about the therapeutic strategies used, especially in countries with multiple ethnic groups.

Examples that illustrate the importance of understanding therapeutic effectiveness responses in target groups include the premature administration of hydroxychloroquine based on affect glycosylation of angiotensin converting enzyme-2, without information on genetic variability (Ferner and Aronson, 2020) and remdesivir administration (Beigel et al., 2020). Research on ethnic group pharmacogenetics in Latin America is still scarce (Sosa-Macías et al., 2016; Leitão et al., 2020), but there is evidence of pharmacogenetic differences (Suarez-Kurtz and Parra, 2018). For example, Mestizo populations are not considered a unique group for these types of studies, since miscegenation varies in each Latin American country (Botton et al., 2019). The COVID-19 pandemic has shown us that data and access to pharmacogenetic information are required for making clinical decisions in a prioritized and sometimes urgent ways.

The reservoirs of genetic material in biobanks in the United Kingdom (McInnes and Altman, 2020) and even in Africa (Matimba et al., 2008), allow researchers to quickly access information on the allelic distributions of important pharmacogenetic markers. However, in Latin America, biobanks for pharmacogenetic research purposes have had only slight development. The bioethical and legal aspects must be considered, and access to biomedical sample information is 
necessary in a region with high ethnical diversity and littlestudied ancestral Amerindian populations.

\section{BIOBANKS}

Biobanks can hold genetic data for a significant percentage of an entire population (Malsagova et al., 2020). In Estonia, e.g., genetic information on about $5 \%$ of the adult population can be found in a DNA bank (Reisberg et al., 2019). Additionally, biobanks contribute to reducing the cost of pharmacogenetic studies (Huttin and Liebman, 2013) avoiding the sampling of the population of interest in each study, also allowing a collaborative approach. In Europe, biobanks like one in Poland, have used different management models, preserving essential fundamental information for the benefit of public health (Sak et al., 2012). Moreover, biobanks are very useful for establishing pharmacogenetic relationships for research drug interactions with genes identified in a population (Muller et al., 2020; Rollinson et al., 2020).

\section{BIOETHICS AND LEGAL ASPECTS}

There are ethical dilemmas involved with asking a donor to provide unique informed consent. This has, however, been

\section{REFERENCES}

Beigel, J. H., Tomashek, K. M., Dodd, L. E., Mehta, A. K., Zingman, B. S., Kalil, A. C., et al. (2020). Remdesivir for the treatment of covid-19-final report. New Engl. J. Med. 0 (0). doi:10.1056/NEJMoa2007764

Botton, M. R., Campos, K. C., Duconge, J., and Scott, S. A. (2019). "Chapter 12pharmacogenomics in Latin American populations," in Pharmacogenomics. 2nd Edn, Editors E. Y. W. F. Lam and S. A. Scott (Academic Press), 329-368.

Facca, D., Smith, M., Shelley, J., Lizotte, D., and Donelle, L. (2020). Exploring the ethical issues in research using digital data collection strategies with minors: a scoping review. PLoS One 15 (8), e0237875. doi:10.1371/journal. pone. 0237875

Ferner, R. E., and Aronson, J. K. (2020). Chloroquine and hydroxychloroquine in covid-19. BMJ 369, m1432. doi:10.1136/bmj.m1432

Hansson, M. G. (2009). Ethics and biobanks. Br. J. Cancer 100 (1), 8-12. doi:10. 1038/sj.bjc.6604795

Harrison, Ch. (2020). Coronavirus puts drug repurposing on the fast track. Nat. Biotechnol. 38 (4), 379-391. doi:10.1038/d41587-020-00003-1

Helgesson, G., Dillner, J., Carlson, J., Bartram, C. R., and Hansson, M. G. (2007). Ethical framework for previously collected biobank samples. Nat. Biotechnol. 25 (9), 973-976. doi:10.1038/nbt0907-973b

Huttin, C. C., and Liebman, M. N. (2013). The economics of biobanking and pharmacogenetics databasing. Technol. Health Care 21 (2), 183-190. doi:10. 3233/THC-130729

Leitão, L. P., Souza, T. P., Rodrigues, J. C., Fernandes, M. R., Santos, S., and Santos, N. P. (2020). The metabolization profile of the CYP2D6 gene in amerindian populations: a review. Genes 11 (3), 262. doi:10.3390/genes11030262

Malsagova, K., Kopylov, A., Stepanov, A., Butlova, T., Sinitsyna, A., Izotov, A., et al. (2020). Biobanks-A platform for scientific and biomedical research. Diagnostics 10, 485. doi:10.3390/diagnostics 10070485

Matimba, A., Oluka, M. N., Ebeshi, B. U., Sayi, J., Bolaji, O. O., Guantai, A. N., et al. (2008). Establishment of a biobank and pharmacogenetics database of African populations. Eur. J. Hum. Genet. 16 (7), 780-783. doi:10.1038/ejhg.2008.49 improved with the development of the model of dynamic consent (Steinsbekk et al., 2013). Ethics committees play a key role in the ethical debates concerning approval of donations to biobanks and access to the stored genetic material (Hansson, 2009). A legal framework is also required for the use of biobank samples (Helgesson et al., 2007). Recently, legal and ethical issues have focused on sample ownership and access, donor protection, and long-term storage of biological samples (Paskal et al., 2018; Facca et al., 2020).

\section{CONCLUSION}

Due to high population diversity, Latin America faces the challenge of addressing genetic variability in studies to improve pharmacological responses to therapeutics for diseases. The creation of biobanks, their strengthening, and collaboration among them, would be a fundamental contribution to obtain pharmacogenetic information and efficient therapeutic responses in Latin America.

\section{AUTHOR CONTRIBUTIONS}

RV and OC designed and drafted the manuscript. Both authors contributed to the article and approved the submitted version.

McInnes, G., and Altman, R. B. (2020). Drug response pharmacogenetics for 200,000 UK biobank participants. bioRxiv. [Preprint]. doi:10.1101/2020.08.09.243311v1

Muller, H., Dagher, G., Loibner, M., Stumptner, C., Kungl, P., and Zatloukal, K. (2020). Biobanks for life sciences and personalized medicine. importance of standarization, biosafety, biosecurity and data management. Curr. Opin. Biotechnol. 65, 45-51. doi:10.1016/j.copbio.2019.12.004

Nabirotchkin, S., Pelufo, A., Rinaudo, Ph., Yu, J., Hajj, R., and Cohen, D. (2020). Next-generation drug repurposing using human genetics and network biology. Curr. Opin. Pharmacol. 51, 78-92. doi:10.1016/j.coph.2019.12.004

Oprea, T. I., Bologa, C. G., Brunak, S., Campbell, A., Gan, G. N., Gaulton, A., et al. (2018). Unexplored therapeutic opportunities in the human genome. Nat. Rev. Drug Discov. 17 (5), 317-332. doi:10.1038/nrd.2018.14

Ovsyannikova, I. G., Haralambieva, I. H., Crooke, S. N., Poland, G. A., and Kennedy, R. B. (2020). The role of host genetics in the immune response to SARS-CoV-2 and COVID-19 susceptibility and severity. Immunological Rev. 296 (1), 205-219. doi:10.1111/imr.12897

Paskal, W., Paskal, A. M., Dębski, T., Gryziak, M., and Jaworowski, J. (2018). Aspects of modern biobank activity-comprehensive review. Pathol. Oncol. Res. 24 (4), 771-785. doi:10.1007/s12253-018-0418-4

Reisberg, S., Krebs, K., Lepamets, M., Kals, M., Mägi, R., Metsalu, K., et al. (2019). Translating genotype data of 44,000 biobank participants into clinical pharmacogenetic recommendations: challenges and solutions. Genet. Med. 21 (6), 1345-1354. doi:10.1038/s41436-018-0337-5

Rollinson, V., Turner, R., and Pirmohamed, M. (2020). Pharmacogenomics for primary care: an overview. Genes 11 (11), 1337. doi:10.3390/genes11111337

Sak, J., Pawlikowski, J., Goniewicz, M., and Witt, M. (2012). Population biobanking in selected European countries and proposed model for a polish national DNA bank. J. Appl. Genet. 53 (2), 159-165. doi:10.1007/s13353-012-0082-4

Sharma, A., Buschmann, M. M., and Gilbert, J. A. (2019). Pharmacomicrobiomics: the holy grail to variability in drug response? Clin. Pharmacol. Ther. 106 (2), 317-328. doi:10.1002/cpt.1437

Sosa-Macías, M., Teran, E., Waters, W., Fors, M. M., Altamirano, C., Jung-Cook, H., et al. (2016). Pharmacogenetics and ethnicity: relevance for clinical implementation, clinical trials, pharmacovigilance and drug regulation in 
Latin America. Pharmacogenomics 17 (16), 1741-1747. doi:10.2217/pgs-20160153

Steinsbekk, K. S., Kåre Myskja, B., and Solberg, B. (2013). Broad consent versus dynamic consent in biobank research: is passive participation an ethical problem? Eur. J. Hum. Genet. 21 (9), 897-902. doi:10.1038/ejhg. 2012.282

Suarez-Kurtz, G., and Parra, E. J. (2018). "Chapter six-population diversity in pharmacogenetics: a Latin American perspective," in Advances in pharmacology. Editors En. K. Brøsen and P. Damkier (Academic Press), Vol. 83, 133-154.
Conflict of Interest: The authors declare that the research was conducted in the absence of any commercial or financial relationships that could be construed as a potential conflict of interest.

Copyright $\odot 2021$ Vargas and Cobar. This is an open-access article distributed under the terms of the Creative Commons Attribution License (CC BY). The use, distribution or reproduction in other forums is permitted, provided the original author(s) and the copyright owner(s) are credited and that the original publication in this journal is cited, in accordance with accepted academic practice. No use, distribution or reproduction is permitted which does not comply with these terms. 